\section{Factors associated with young children exhibiting picky eating behaviour}

\begin{tabular}{|c|c|c|}
\hline $\begin{array}{l}\text { Picky eating in preschool } \\
\text { children is a well-documented } \\
\text { phase when children are } \\
\text { reluctant to try new foods and// } \\
\text { or show very strong preferences } \\
\text { for particular foods. This } \\
\text { behaviour can create concern } \\
\text { for parents, and this has created } \\
\text { a whole market for advice and } \\
\text { guidance, not all of which is } \\
\text { evidence-based. Dr Pauline } \\
\text { Emmett and Dr Caroline Taylor, } \\
\text { from the Centre for Academic } \\
\text { Child Health at the University } \\
\text { of Bristol, explore factors } \\
\text { associated with picky eating to } \\
\text { determine whether this should } \\
\text { be a source of worry for parents. }\end{array}$ & $\begin{array}{l}\text { icky eating is usually classified } \\
\text { as part of a spectrum of feeding } \\
\text { difficulties observed in children. } \\
\text { Strong food preferences and suspicion } \\
\text { of new foodd in childhood may have } \\
\text { had evolutionary benefits by reducing } \\
\text { the risk of consuming toxins. However, } \\
\text { in the modern world, these behaviours } \\
\text { can provide a barrier to the acceptance } \\
\text { of certain food items. This often causes } \\
\text { concern amongst parents about nutrient } \\
\text { intake and the risk of poor future health } \\
\text { outcomes. Determining whether this } \\
\text { behaviour is problematic is an important } \\
\text { public health issue. } \\
\text { DEFINING AND } \\
\text { MEASURING PICKY EATING } \\
\text { There is no single widely accepted } \\
\text { definition of picky eating, and therefore } \\
\text { there is little consensus on how } \\
\text { to measure it, resulting in a huge variety of } \\
\text { prevalence estimates. Dr Pauline Emmett } \\
\text { and Dr Caroline Taylor and their team } \\
\text { investigated the range of methods used to } \\
\text { assess picky eating as well as the different } \\
\text { sources of data used to determine } \\
\text { prevalence. Researchers reviewed the } \\
\text { literature on picky eating between } 1990 \\
\text { and } 2015 \text { and found that most studies on } \\
\text { picky eating were cross-sectional, which } \\
\text { means that they only look at behaviours } \\
\text { and associated factors at one poivt in } \\
\text { time. Such methods, therefore, do not } \\
\text { allow for exploring the prevalence of } \\
\text { picky eating over time or the potential } \\
\text { health-related outcomes of the behaviour. } \\
\text { Emmett and Taylor found a wide } \\
\text { range of tools uned to assess } \\
\text { picky eating, including the } \\
\text { Children's Eating Behaviour } \\
\text { Questionnaire and } \\
\text { the Child Feeding } \\
\text { Questionnaire }\end{array}$ & $\begin{array}{l}\text { as well as study-specific questions. } \\
\text { In addition, a variety of prevalence rates } \\
\text { were found of picky eating, spanning from } \\
6 \% \text { to } 50 \% \text {. One of the few sources of } \\
\text { longitudinal data, where participants are } \\
\text { followed for an extended period of time, } \\
\text { is the Avon Longitudinal Study of Parents } \\
\text { and Children (ALSPAC). The prevalence } \\
\text { of children being very picky eaters (based } \\
\text { on a question about definite likes and } \\
\text { dislikess in ALSPAC varied with age from } \\
10 \% \text { to } 15 \% \text {, with the peak prevalence } \\
\text { at } 38 \text { months. } \\
\text { PREDICTORS ASsOCIATED } \\
\text { WITH PICKY EATING } \\
\text { Researchers have also investigated } \\
\text { factors which can predict picky eating } \\
\text { in children. ALSPAC data was used } \\
\text { to measure picky eating at age } 3 \text { years } \\
\text { and then explore potential antecedents } \\
\text { of this behaviour. It was found that } \\
\text { feeding difficulties during complementary } \\
\text { feeding and the late introduction of } \\
\text { lumpy foods (after } 9 \text { months) were both } \\
\text { associated with an increased likelihood } \\
\text { of the child being a picky eater. A strong } \\
\text { predictor was the child being choosy } \\
\text { at } 15 \text { months, particularly if the mother } \\
\text { was worried about this behaviour. At } 15 \\
\text { months, the majority (56\%) of children } \\
\text { were considered to be choosy with food. } \\
\text { Of these childrren, } 17 \% \text { became very } \\
\text { picky at age } 3 \text { years if the mother was not } \\
\text { worried, in contrast to } 50 \% \text { if the mother } \\
\text { was greatly worried about the choosy } \\
\text { behaviour. Feeding ready-prepared } \\
\text { food was also a predictive factor for later } \\
\text { picky eating. Protective factors against } \\
\text { picky eating were the mother providing } \\
\text { fresh fruit and eating the same meal } \\
\text { as her child. } \\
\text { In light of these results, Emmett and } \\
\text { Taylor suggest that the likelihood of picky }\end{array}$ \\
\hline
\end{tabular}

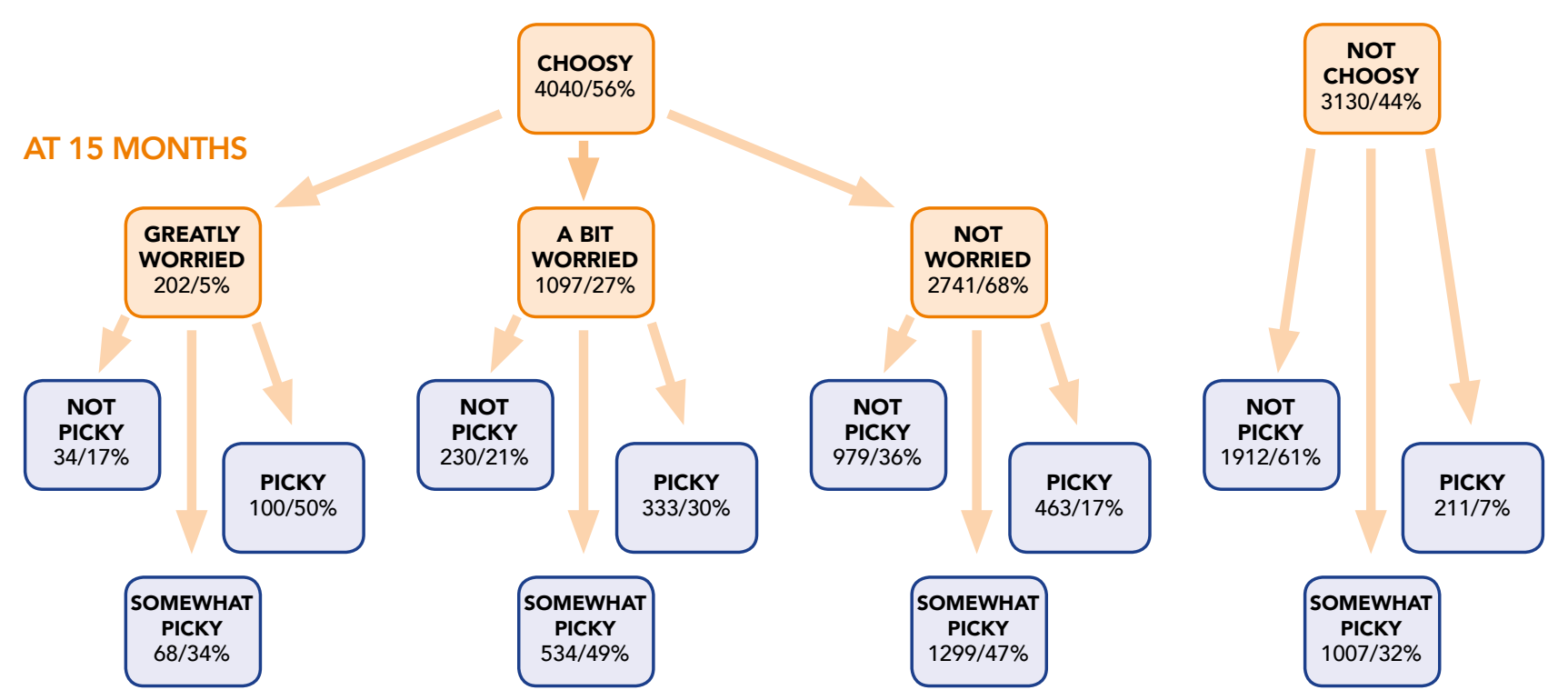

AT 38 MONTHS

eating can be reduced by providing foods that help the chll to lean to chew from through the second year of life when children have a natural tendency to be wary of new foods, providing fresh fruit for the child, the mother often eating the same meal as the child and feeding the child home-prepared fresh foods. They also emphasise that parents should be reassured that picky eating is normal and to continue to provide a variety of foods.

\section{FACTORS ASSOCIATED}

WITH MATERNAL WORRY

weres associated with matenal worny were explored by Emmett and Taylor with higher levels of picky eating behaviour in children Researchers used ALSPAC data again to meachers used of worry amongst parents about choosy behaviour in their children at 15 months of age. They also investigated feeding behaviours and practices throughout the first 15 months to determine predictors of this worry.

It was found that half of the children (56\%) were described as choosy at 15 months. Amongst these children, $27 \%$ had mothers who were a bit worried and $5 \%$ greatly worried. Mothers were more likely to be worried if their child was first bom and/or difcull to feed or refused solids by 6 months of age. to have introduced lumpy foods late
The figure shows the relationship between early choosiness, maternal worry about that choosiness
and later picky aating behaviour.
A strong predictor of preschool-age picky eating was the child being choosy with food at 15 months, particularly if the mother was worried about this behaviour. (after 9 months). If mothers fed their child vegetables regularly by age 6 months, this was associated with a lower risk of being worried about choosy behaviour eaters, which contributed non-picky intake. Picky eaters were also more likely providing support and advice to parents to have hard stools than non-picky eaters, when they begin complementary feeding which was explained by the difference could help to alleviate worries about in fibre consumption. Researchers suggest through a number of different strategies. $\begin{array}{ll}\text { Picky eating has been suggested } & \text { These include encouraging parents } \\ \text { to repeatedly offer their children smal }\end{array}$ to be associated with an increased risk amounts of fruit and vegetables to of constipation, as a result of a lower fibre overcome neophobia (fear of trying intake. Emmett and Taylor used ALSPAC new foods), to provide an example for data to determine dietary fibre intake at children by eating fruits and vegetables was predictive of stool hardness at 42 mealtimes with the same meal being months. Picky eating at both these time offered but not forced onto children. points was also investigated. Researchers

\begin{tabular}{|l|l|l|} 
& $\begin{array}{l}\text { \% FIBRE FROM } \\
\text { VEGETABLES (95\% CI) }\end{array}$ & \\
\hline Picky eaters & $8.9(8.2,9.7)$ & \\
\hline Non-picky eaters & $15.7(15.5,15.9)$ & $p<0.001$ \\
\hline
\end{tabular}
who are picky eaters consumed fewer
fruits and vegetables than non picky 38 months and then to see whether this themselves and to adopt regular family 


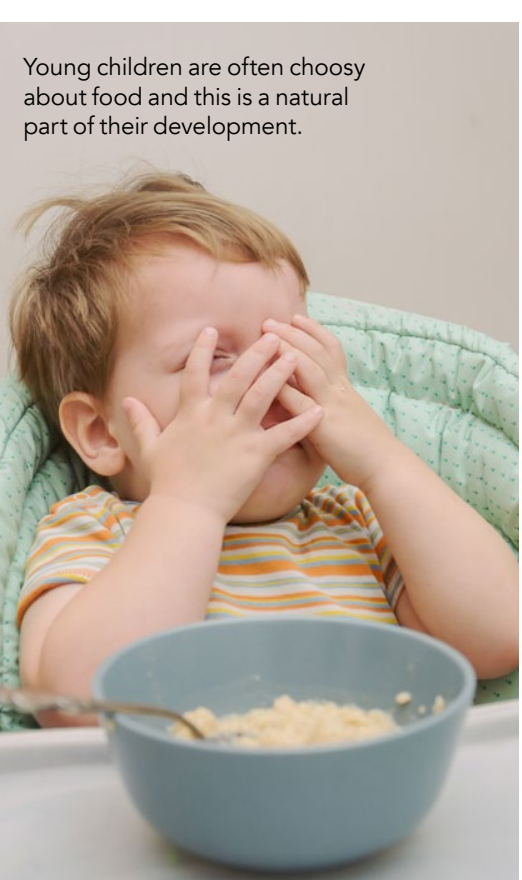

\section{MACRO-AND}

MICRONUTRIENT INTAKES

Macro- and micronutrient intakes are eating. Emmett and Taylor used ALSPAC data to measure both picky eating and nutrient intakes when children were aged 3 and 7 years. It was found that picky eaters at age 3 years had lower mean carotene, iron, and zinc intakes than nonpicky eaters. This was also found at age 7 years. Iron and zinc were the nutrients most likely to have intakes in picky eaters below recommended amounts, with free sugars intake much higher than recommended for optimal health. There were no significant differences in energy were ade average requirements for energy.

The differences in nutrient intakes were explained by lower intakes of meat fish, vegetables and fruits in picky eaters than non-picky eaters. Picky eaters also had higher intakes of sugary foods and drinks

\begin{tabular}{|l|l|l|} 
& $\begin{array}{l}\text { Usually hard stool, without fibre } \\
\text { adjustment (OR (95\% CI)) }\end{array}$ & $\begin{array}{l}\text { Usually hard stool, with fibre } \\
\text { adjustment (OR }(95 \% \text { CII)) }\end{array}$ \\
\hline Not a picky & 1.00 (ref) & $1.00($ (ref) \\
\hline Picky eater & $1.31(1.07,1.61)$ & $0.65(0.32,1.35)$ \\
\hline & $\mathrm{p}=0.010$ & $\mathrm{p}=0.248$ \\
\hline
\end{tabular}

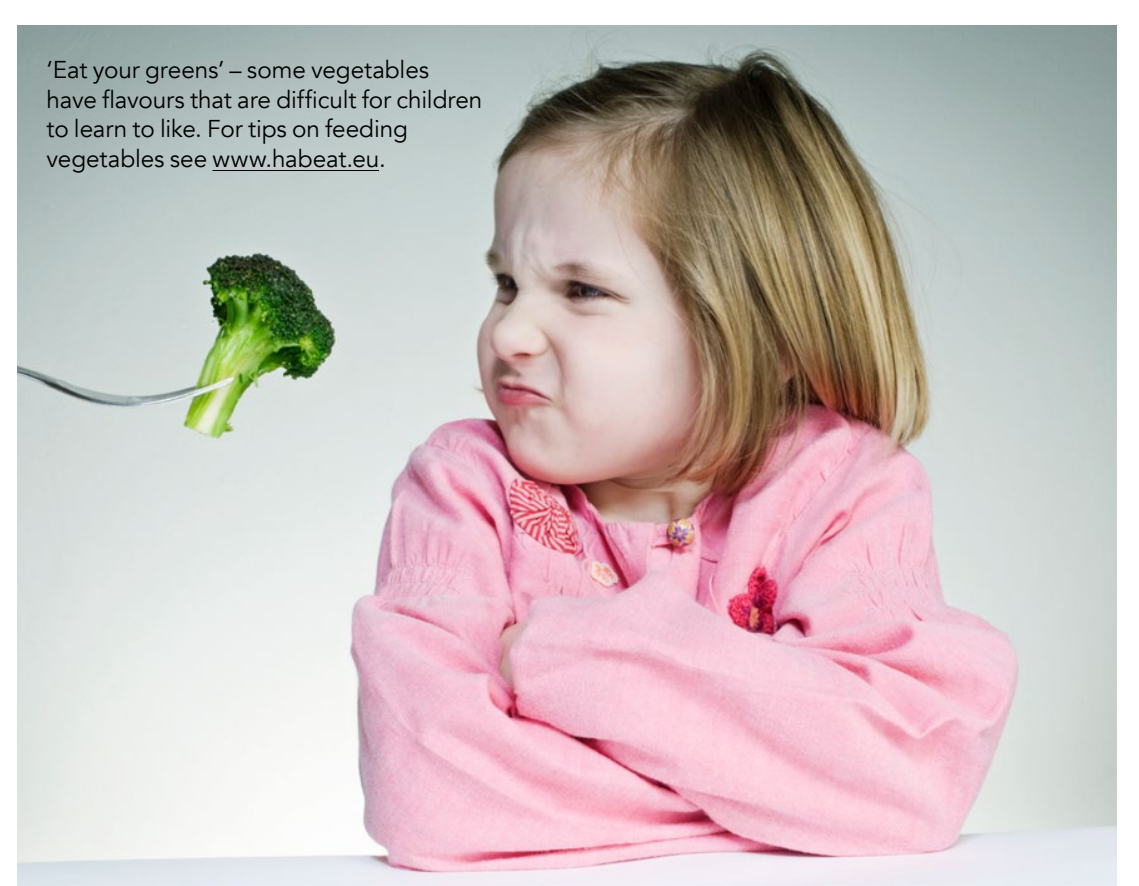

Protective factors against picky eating were the mother providing fresh fruit and eating the same meal as her child.

than non-picky eaters at age 7 years. Researchers suggest that alleviating smaller and lighter than non-picky eaters having inadequate nutrient intakes should between gere no significant differences between groups in terms of body fat. of picky eaters were consistently above
the $50^{\text {th }}$ centiles of reference growth charts GROWTH AND BODY COMPOSIION IN PICKY EATERS A further worry with picky eaters is the potential wisk of being underweight investigated whether picky eaters were different in terms of height, weight and body composition from non-picky eaters using ALSPAC data. Children were measured on seven occasions between the ages of 7 and 17 years. no evidence of an increased likelihood of icky eaters were more likely to which indicates that the majority were growing normally. More than two-thirds of picky eaters were not thin at any age point. However, almost one-fith of the very picky eaters were thin at three or one-tenth of non-picky eaters There was being overweight or obese in either the

\section{CONCLUSIONS}

Overall, findings from research by Emmett and Taylor suggest that picky eating in children is a normal part of growing up and parents need not be overly concerned about this behaviour. However, there are a number of strategies that parents can employ to reduce the risk of picky eating. These include encouraging children to eat a varied diet, including fresh fruit and vegetables, as well as setting an example by eating
a varied diet with their children.

p.m.emmett@bristol.ac.uk T: $44(0) 1174283096$ W: www.bristol.ac.uk/social-community-medicine/people/pauline-m-emmet (163-7a986a7960eb)

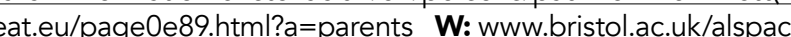

caroline mtaylor@bristol.ac.uk T: 44 (0)117 4283099 W: www.bristol.ac.uk/social-community-medicine/people/person/ aroline-m-taylor/overview.html @: @carolineltaylor

\section{Research Objectives}

Dr Pauline Emmett and Dr Caroline Taylor from the Centre for Academic Child Health, Bristol Medical School, University of Bristol use data from the Avon Longitudinal Study of Parents and Children (ALSPAC), which is a long-term research project that enrolled more than 14,000 pregnant women in 1991 and 1992. It has followed the resulting offspring and their parents since recruitment using questionnaires and clinic visits. The research seeks to investigate factors associated with picky eating to determine whether as behaviour should be a source of thonc

\section{Detail}

Centre for Academic Child Health

Population Health Sciences

Bristol Medical School

University of Bristol

1-5 Whiteladies Road

Bristol BS8 1NU, UK

Bios

Dr Pauline Emmett: Senior Research Fellow (semi-retired), Centre for Academic Child Health, Bristol Medical School,

University of Bristol. Experienced research Nutritionist

and Dietician. Oversaw Nutrition Research for the Avon

Longitudinal Study of Parents and Children (ALSPAC) for years. Interested in nutrition in pregnancy and childhood

particularly early growth and development of children.

Dr Caroline Taylor: Research Fellow, Centre for

Academic Child Health, Bristol Medical School, University

in pregnancy and childhood, particularly in how diet

and the environment in pregnancy affect the growth

and development of the child.

Funding

The UK Medical Research Council and the Wellcome Trust (Grant ref: 102215/2/13/2) and the University of Bristol provide core support for ALSPAC. The research

on picky eating is funded by Nestlé Nutrition.

- Dr Caroline Taylor is funded by a Wellcome Career Re-Entry Fellowship (Grant ref: 104077/Z/14/Z).

\section{㢦还 University of 6. BRISTOL}

\section{References}

Taylor, C. M., Wernimont, S. M., Northstone, K., \& Emmett, P. assessment, prevalence and dietary intakes'. Appetite, 95,

349-359.

Taylor, C. M., Northstone, K., Wernimont, S. M., \& Emmett, P. M. (2016). 'Macro-and micronutrient intakes in picky eaters: a cause for concern?'. Taylor, C. M., Northstone, K., Wernimont, S. M., \& Emmett, with dietary fibre intakes and stool hardness'. Appetite, 100 263-271.

Emmett, P., Hays, N., \& Taylor, C. (2018). 'Factors associated with maternal worry about her young child exhibiting choosy feeding behaviour. International Journal of Environmental esearch and Public Health, 15(6), 1236. Emmett, P. M., Hays, N. P., \& Taylor, C. M. (2018). 'Antecedents of picky eating behaviour in young children'.

Taylor, C. M., Steer, C. D., Hays, N. P., \& Emmett, P. M. (2018) eaters: a longitudinal view'. European Journal of Clinical Nutrition, doi: 10.1038/s41430-018-0250-71.

\section{Personal Response}

Are there other questions about picky eating that you both plan to investigate using the ALSPAC data?

I We would be very interested to investigate long-tern picky eaters, that is children who are picky eaters over many years, to assess if this has a greater effect on the diet and health than short-term picky eating. It would also be valuable to find outwhether intakes between picky and non-picky children ages 3 and 7 years persist into the teenage years. Some children who are picky at young ages are not picky at later ages and it would be helpful to determine factors that predict this change, and which might provide an evidence-
base for advice. 